\title{
The effect of ketorolac and
}

\author{
Chunwoo Yang ${ }^{1}$, Sung Mee Jung 2 , Yu Kyung Bae ${ }^{2}$, and Sang-Jin Park ${ }^{2}$ \\ Department of Anesthesiology and Pain Medicine, ${ }^{1}$ Inha University School of Medicine, Incheon, ${ }^{2}$ Yeungnam \\ University School of Medicine, Daegu, Korea
}

Background: We evaluated the effect of two drugs with anti-inflammatory action, dexamethasone and ketorolac, on reduction of postoperative sore throat (POST) after general anesthesia with endotracheal intubation in patients undergoing thyroidectomy.

Methods: One hundred and ninety-two female patients scheduled to undergo general anesthesia with endotracheal intubation for thyroidectomy were enrolled in this prospective study. Participants were randomly allocated to receive intravenous medication; placebo (Group C, $\mathrm{n}=45$ ), ketorolac $30 \mathrm{mg}$ immediately before intubation (Group Kpre, $\mathrm{n}=47$ ), ketorolac $30 \mathrm{mg}$ at the end of surgery (Group Kpost, $\mathrm{n}=45$ ) and dexamethasone $10 \mathrm{mg}$ (Group D, $\mathrm{n}=43$ ). The incidence and severity of POST and hoarseness were evaluated at 1, 6 and 24 hours after surgery.

Results: Incidences and severities of POST at rest and during swallowing in first 6 hours after extubation were comparable among 4 groups. At 24 hours postextubation, the incidence ( $\mathrm{P}=0.002,95 \% \mathrm{CI}$ of proportion differences; $0.05-0.39$ ) and severity $(\mathrm{P}=0.008)$ of POST during swallowing were significantly lower in group $\mathrm{D}$ than in group C. Kpre and Kpost groups did not show a greater reduction in POST than group C, despite lower rescue analgesic requirement at 1 hour after extubation in group Kpre ( $\mathrm{P}=0.006 ; 95 \% \mathrm{CI}$ of proportion differences; $0.07-0.38)$. No intergroup differences were observed in incidences of hoarseness or adverse events.

Conclusions: Intravenous administration of dexamethasone $10 \mathrm{mg}$, but not ketorolac, before induction of anesthesia reduces the incidence and severity of POST during swallowing at 24 hours after thyroidectomy.

Key Words: Dexamethasone, Hoarseness, Intubation, Ketorolac, Sore throat, Thyroidectomy.

Corresponding author: Sung Mee Jung, M.D., Ph.D.

Department of Anesthesiology and Pain Medicine, Yeungnam University School of Medicine, 170, Hyeonchung-ro, Nam-gu, Daegu 42415, Korea

Tel: 82-53-620-3368, Fax: 82-53-626-5275

Email: applejsm@gmail.com

ORCID: http://orcid.org/0000-0001-5602-9011

Received: July 27, 2016.

Revised: August 23, 2016 (1st); October 5, 2016 (2nd).

Accepted: October 12, 2016.

Korean J Anesthesiol 2017 February 70(1): 64-71

https://doi.org/10.4097/kjae.2017.70.1.64

\section{Introduction}

Postoperative sore throat (POST) is a minor but common postoperative problem following general anesthesia with tracheal intubation. Although diverse pathophysiology has been implicated, irritation of posterior pharynx, larynx and trachea by endotracheal tube (ETT) itself and airway instrumentation (direct laryngoscopy and intubation) leading to inflammatory response in airway mucosa plays a major role in the development of POST. Thyroidectomy is especially associated with high incidence of POST ranging from $61 \%$ to $100 \%$ during the first

(c) This is an open-access article distributed under the terms of the Creative Commons Attribution Non-Commercial License (http://creativecommons.org/ licenses/by-nc/4.0/), which permits unrestricted non-commercial use, distribution, and reproduction in any medium, provided the original work is properly cited. 
24 hours after tracheal intubation [1-4], since ETT movement in the trachea due to neck hyperextension and manipulation of tissues surrounding airway during surgery may intensify mucosal irritation and inflammation in the trachea. Although sore throat usually resolves spontaneously in a few days, POST is likely to be the most common complaint and major cause of distress because intensity of postoperative pain after thyroidectomy is usually lower than that after major surgery. Thus, prevention of POST is a great concern in terms of improving patient's satisfaction in patients undergoing thyroidectomy.

Considering the involvement of inflammation in pathophysiology of POST, the use of steroidal or non-steroidal antiinflammatory drug may be an effective pharmacological strategy to prevent POST after tracheal intubation. Corticosteroid exerts its anti-inflammatory and anti-emetic efficacy by inhibiting phospholipase A2 and consequently blocking production of arachidonic acid and inflammatory mediators such as prostaglandin and leukotriene. Previous studies showed that a single dose of intravenous (IV) dexamethasone decreases the incidence of POST after different types of surgery [5-7]. However, it has not been determined whether a single dose of dexamethasone can effectively reduce POST in high risk patients, such as women undergoing thyroidectomy.

Ketorolac is a non-steroidal anti-inflammatory drug (NSAID) with analgesic, anti-inflammatory and antipyretic activities by inhibiting cyclooxygenase, which is involved in the synthesis of prostaglandin. Because of its great analgesic efficacy, ketorolac is commonly administered IV as a single dose or supplement to opioid analgesic to relieve acute postoperative pain. Both topical and oral administration of ketorolac have been reported an anti-inflammatory efficacy equivalent to that of dexamethasone by suppressing acute pain and swelling after cataract and dental procedures [8,9]. However, no single study has compared the anti-inflammatory efficacies of intravenous dexamethasone and ketorolac in terms of the prevention of POST after thyroidectomy.

Therefore, this study was to determine whether a single IV dose of ketorolac $30 \mathrm{mg}$ or dexamethasone $10 \mathrm{mg}$ reduces the incidence and severity of POST than placebo in female patients undergoing thyroidectomy. The primary outcome was the incidence of POST at 6 hours after extubation.

\section{Materials and Methods}

This prospective, randomized, double-blinded study was approved by the Institutional Review Board of our Hospital (YUH-13-0492-M88) and registered at ClinicalTrials.gov (NCT02039427). After obtaining written informed consent from all participants during a preoperative visit, 192 adult female patients aged between 20 and 65 years, American Society of Anesthesiologists physical status I or II scheduled for primary thyroidectomy under general anesthesia with endotracheal intubation and immediate postoperative extubation, were enrolled. Exclusion criteria were known tracheal pathology, tracheostomy, previous head and neck surgery, recent upper respiratory tract infection within 6 weeks, a body mass index exceeding $35 \mathrm{~kg} /$ $\mathrm{m}^{2}$, inflammation or hemorrhage in the upper gastrointestinal tract, use of non-steroidal anti-inflammatory drug or steroid medication within 24 hours, allergy to the general anesthetic used in this study, known or suspected difficult airway and expected duration of surgery exceeding 180 minutes. Patients that underwent reoperation during the first 24 hours postoperatively were also excluded from final analysis.

After arriving in the preoperative holding area, patients were randomly assigned to 1 of 4 groups using a computer-generated random assignment scheme: Group C; placebo (normal saline) injections at 5 minutes before induction of anesthesia and 10 minutes before end of surgery, Group Kpre; ketorolac $30 \mathrm{mg}$ injection at 5 minutes before induction of anesthesia and placebo injection at 10 minutes before end of surgery, Group Kpost; placebo injection at 5 minutes before induction of anesthesia and ketorolac $30 \mathrm{mg}$ injection at 10 minutes before end of surgery, Group D; Dexamethasone $10 \mathrm{mg}$ injection at 5 minutes before induction of anesthesia and placebo injection at 10 minutes before end of surgery. Each study drug was made at the same volume $(2 \mathrm{ml})$ by a nurse blinded to group assignment on the morning of surgery.

No patient received premedication before anesthesia. Standard monitoring in the operating room included pulse oximetry, electrocardiogram and noninvasive blood pressure. General anesthesia was induced with bolus injection of propofol 1.5-2 $\mathrm{mg} / \mathrm{kg}$ and continuous infusion of remifentanil $(0.5-1.0 \mu \mathrm{g} / \mathrm{kg} /$ $\mathrm{min})$. After complete neuromuscular block with rocuronium 0.5-0.7 mg/kg, direct laryngoscopy was performed using a Macintosh blade (size 3). The trachea was intubated with a 7.0 to 7.5 $\mathrm{mm}$ inner diameter ETT with tapered cuff (TaperGuard ${ }^{\mathrm{TM}}$ oral/ nasal tracheal tube, Covidien, Boulder, CO, USA). Intubation was performed by at least 2 years of experienced residents who were blinded to the group assignment. The ETT was lubricated with tap water before intubation and inflated with room air until no air leakage could be heard after intubation. Intracuff pressure was also measured immediately after intubation and checked every 30 minutes using a handheld cuff pressure gauge (VBM Medizintechnik GmbH, Sulz am Neckar, Germany) to keep at 20 to $25 \mathrm{mmHg}$ throughout surgery. Anesthesia was maintained with $1.5-2 \%$ sevoflurane in $50 \%$ oxygen in air at a total flow rate of $3 \mathrm{~L} / \mathrm{min}$ and remifentanil was infused based on the surgical stimulus and hemodynamic response. Anesthetic depth was monitored using Bispectral Index monitor (BIS VISTA ${ }^{\mathrm{TM}}$ Monitoring System; Covidien, Boulder, CO, USA) and BIS levels be- 
tween 40 and 60 were deemed adequate for surgery. Rocuronium was administered to less than two responses of train-of-four (TOF) stimulation using TOF Watch SX (Organon, Dublin, Ireland) to minimize the effect of inadequate relaxation or movement. At the end of surgery, residual neuromuscular blockade was antagonized by pyridostigmine and glycopyrrolate. When response to verbal commands, adequate spontaneous breathing and a TOF ratio greater than 0.9 were achieved, patients were extubated after gentle oropharyngeal suction. Postoperative pain was treated using IV injection of fentanyl $50-100 \mu \mathrm{g}$ as required in post-anesthetic care unit (PACU). No patients received IV patient-controlled analgesia.

Intubating condition was assessed by the anesthesiologist who performed each intubation using Cormack and Lehane classification: grade 1, complete visualization of the vocal cords; grade 2, visualization of the inferior portion of the glottis; grade 3 , visualization of only the glottis; grade 4, nonvisualized epiglottis. At 1, 6 and 24 hours after extubation, the incidences and severities of sore throat, hoarseness and pain were assessed by an independent investigator unaware of group assignments. POST was defined as discomfort at larynx or pharynx at rest and during swallowing after surgery and was assessed using a 4-grade scale (0-3) based on verbal responses to questions: 0 , none; 1 , mild (less severe than with a cold); 2 , moderate (similar with a cold); 3 , severe (more severe than with a cold) [10]. Incidence of POST was defined as the number of patients who reported a sore throat grade of greater than 0 during the $24 \mathrm{~h}$-evaluation period. Postoperative hoarseness $(\mathrm{PH})$ was assessed using a 4 -grade scale (0-3): 0 , none; 1 , mild (noticed by the patient only); 2 , severe (obvious to observer); 3 , aphonia (silence of voice)[11]. The presence of $\mathrm{PH}$ was defined as a hoarseness grade greater than 0 during the $24 \mathrm{~h}$-evaluation period. All patients were asked where they felt discomfort or pain when arriving in the post-anesthetic care unit. Postoperative pain at surgical site was assessed using a numerical rating scale (NRS, $0=$ no pain; $10=$ worst imaginable pain). Potential side effects associated with the study drugs, such as nausea, vomiting, gastritis, gastric bleeding, headache, skin rash, renal failure, hyperglycemia, wound infection, and itching were also recorded.

A power analysis was performed to determine the sample size based on the data from a previous study, which reported $84 \%$ incidence of POST at 6 hours after thyroidectomy [2]. A minimum of 41 participants per group was required to detect a $40 \%$ reduction in the incidence of POST at rest with a power $(1-\beta)$ of $80 \%$ at a set type I error ( $\alpha$ ) of 0.05 between groups. We enrolled 48 patients in each group, taking into consideration of $15 \%$ drop-out rate.

Statistical analysis was performed using SPSS version 21 (SPSS Inc., Chicago, IL, USA). Normality of continuous variables was assessed using the Kolmogorov-Smirnov test with Lilliefors cor- rection. Normally distributed continuous variables are presented as mean \pm SD and compared using the one-way analysis of variance followed by Bonferroni's post hoc test. Non-normally distributed continuous variables are presented as median and interquartile range and compared using the nonparametric KruskalWallis test followed by the Mann-Whitney $U$ test. When a significant intergroup difference was found among 4 groups ( $\mathrm{P}$ $<0.05$ ), statistical significance was accepted for $P$ value $<0.0083$ between each group after Bonferroni-adjustment for 6 pairwise comparisons $(0.05 / 6)$. Categorical variables are presented as number (percentage) and analyzed using the $\chi^{2}$ or the Fisher exact test as appropriate. When a significant intergroup difference was found among 4 groups $(\mathrm{P}<0.05)$, statistical significance was accepted for $\mathrm{P}$ value $<0.0083$ after Bonferroni-adjustment for 6 pairwise comparisons $(0.05 / 6)$. Wilson score interval without continuity correction [12] was also used to compare Bonferroniadjusted 95\% confidence interval for pairwise differences in the proportion of patients with sore throat or hoarseness at each time-point. The overall treatment effect on the incidences of sore throat and hoarseness over the 3 measurement times between groups was compared using the modified Mantel-Haenszel test adjusting for the within-patient correction.

\section{Results}

One hundred and ninety-two female patients who underwent thyroidectomy from October 2013 to October 2015 were consecutively enrolled in this study (Fig. 1). After randomized allocation, 12 patients were excluded because of steroid medication (one), anaphylactic reaction to antibiotic resulting in unexpected cancellation of surgery (one) and longer duration of surgery (two), withdrawal of the consent (one), and loss of follow-up (seven). Therefore, a total of 180 patients were included in the final analysis. Demographic, intubation and surgical characteristics were comparable among groups (Table 1).

Incidences of POST are shown in Table 2. At rest, the incidence of POST was similar in the groups at each time during the first 24 hours after extubation. During swallowing, the incidences of POST were also similar at 1 and 6 hours $(\mathrm{P}=1.000$ and $\mathrm{P}=0.079$, respectively) but significantly different at 24 hours $(\mathrm{P}$ $=0.022$ ). Intergroup analysis revealed that group $C$ had a higher incidence of POST during swallowing than group D $(\mathrm{P}=$ 0.002, Bonferroni-adjusted 95\% confidence interval for proportion differences; 0.05-0.39), but not a higher incidence than either ketorolac group, at 24 hours after extubation. The overall treatment effect of dexamethasone compared to control on the incidence of sore throat during swallowing over 3 measurement times during postoperative 24 hours was estimated as odds ratio of 0.17 (95\% CI, 0.06-0.46; P < 0.001).

Severities of POST in thyroidectomy patients are shown in 


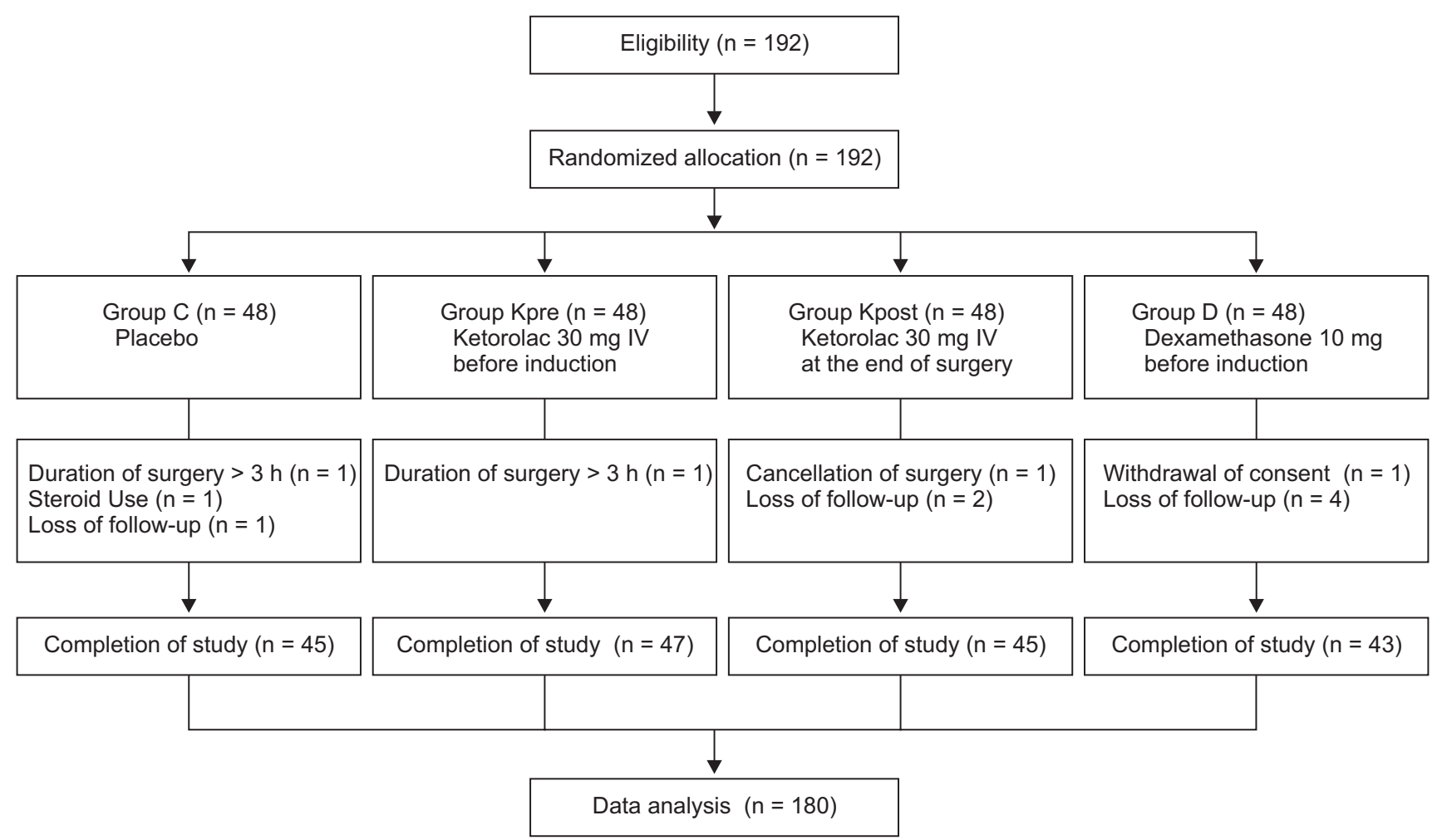

Fig. 1. Flow Diagram of Participants.

Table 1. Demographic and Baseline Characteristics

\begin{tabular}{|c|c|c|c|c|c|}
\hline & $\begin{array}{l}\text { Group C } \\
(\mathrm{n}=45)\end{array}$ & $\begin{array}{l}\text { Group Kpre } \\
\quad(\mathrm{n}=47)\end{array}$ & $\begin{array}{l}\text { Group Kpost } \\
\quad(\mathrm{n}=45)\end{array}$ & $\begin{array}{l}\text { Group D } \\
(\mathrm{n}=43)\end{array}$ & $P$ value \\
\hline Age (yr) & $48.2 \pm 10.1$ & $49.5 \pm 9.2$ & $47.3 \pm 9.3$ & $46.0 \pm 11.1$ & 0.402 \\
\hline Body Mass Index $\left(\mathrm{kg} / \mathrm{m}^{2}\right)$ & $24.1 \pm 3.0$ & $24.0 \pm 3.0$ & $24.8 \pm 3.6$ & $24.6 \pm 3.2$ & 0.577 \\
\hline ASA PS & & & & & 0.141 \\
\hline I & $38(84.4)$ & $42(89.4)$ & $32(71.1)$ & $34(79.1)$ & \\
\hline II & $7(15.6)$ & $5(10.6)$ & $13(28.9)$ & $9(20.9)$ & \\
\hline Denture & $2(4.4)$ & 0 & $2(4.4)$ & $1(2.3)$ & 0.542 \\
\hline Smoker & $1(2.2)$ & $1(2.1)$ & 0 & 0 & 1.000 \\
\hline Cormack-Lehane Grade & & & & & 0.514 \\
\hline 1 & $42(93.3)$ & $43(91.5)$ & $40(88.9)$ & $36(83.7)$ & \\
\hline 2 & $3(6.7)$ & $4(8.5)$ & $4(8.9)$ & $7(16.3)$ & \\
\hline 3 & 0 & 0 & $1(2.2)$ & 0 & \\
\hline Intubation attempt $>2$ & $1(2.2)$ & $4(8.5)$ & $3(6.7)$ & $3(7.0)$ & 0.656 \\
\hline ID of ETT $(\mathrm{mm})$ & & & & & 0.569 \\
\hline 7.0 & $9(20.0)$ & $10(21.3)$ & $10(22.2)$ & $5(11.6)$ & \\
\hline 7.5 & $35(80.0)$ & $37(78.7)$ & $36(77.8)$ & $38(88.4)$ & \\
\hline Bloodstain on ETT & $1(2.2)$ & $4(8.5)$ & $3(6.7)$ & $1(2.3)$ & 0.460 \\
\hline \multicolumn{6}{|l|}{ Duration (min) } \\
\hline Surgery & $95.6 \pm 28.5$ & $102.1 \pm 27.6$ & $105.7 \pm 30.8$ & $100.4 \pm 37.4$ & 0.485 \\
\hline Anesthesia & $118 \pm 28.5$ & $125.3 \pm 28.7$ & $127.9 \pm 30.8$ & $124.9 \pm 40.0$ & 0.533 \\
\hline Intubation & $111.7 \pm 28.5$ & $115.3 \pm 32.5$ & $120.9 \pm 31.4$ & $118.2 \pm 38.1$ & 0.581 \\
\hline Recovery & $7.2 \pm 3.6$ & $6.8 \pm 2.7$ & $7.8 \pm 3.3$ & $7.3 \pm 3.2$ & 0.526 \\
\hline
\end{tabular}

Data are presented as number of patients (\%) or mean \pm SD. ASA PS: American society of anesthesiologists physical status, Recovery: from end of surgery to extubation, ID: internal diameter, ETT: endotracheal tube. 
Table 2. Incidence of Sore Throat and Hoarseness in the First 24 Hours after Thyroidectomy

\begin{tabular}{|c|c|c|c|c|c|}
\hline & $\begin{array}{l}\text { Group C } \\
(\mathrm{n}=45)\end{array}$ & $\begin{array}{l}\text { Group Kpre } \\
\quad(\mathrm{n}=47)\end{array}$ & $\begin{array}{l}\text { Group Kpost } \\
\quad(\mathrm{n}=45)\end{array}$ & $\begin{array}{c}\text { Group D } \\
(\mathrm{n}=43)\end{array}$ & $P$ value \\
\hline \multicolumn{6}{|c|}{ Sore throat } \\
\hline \multicolumn{6}{|c|}{ Rest } \\
\hline $1 \mathrm{~h}$ & $43(95.6)$ & 44 (93.6) & $42(93.3)$ & $41(93.0)$ & 1.000 \\
\hline $6 \mathrm{~h}$ & $32(71.1)$ & $34(72.3)$ & $33(73.3)$ & $25(58.1)$ & 0.377 \\
\hline $24 \mathrm{~h}$ & $20(44.4)$ & $21(44.7)$ & $25(55.6)$ & $15(34.9)$ & 0.283 \\
\hline \multicolumn{6}{|c|}{ Swallowing } \\
\hline $1 \mathrm{~h}$ & $44(97.8)$ & 45 (95.7) & $44(97.8)$ & $42(97.7)$ & 1.000 \\
\hline $6 \mathrm{~h}$ & $44(97.8)$ & $42(89.4)$ & 40 (88.9) & $35(81.4)$ & 0.079 \\
\hline $24 \mathrm{~h}$ & $42(93.3)$ & $37(78.7)$ & $37(82.2)$ & $29(67.4)^{*}$ & 0.022 \\
\hline \multicolumn{6}{|c|}{ Hoarseness } \\
\hline $1 \mathrm{~h}$ & $42(93.3)$ & $44(93.6)$ & $40(88.9)$ & $40(93.0)$ & 0.867 \\
\hline $6 \mathrm{~h}$ & $37(82.2)$ & $36(76.6)$ & $39(86.7)$ & $35(81.4)$ & 0.666 \\
\hline $24 \mathrm{~h}$ & $34(75.6)$ & $28(59.6)$ & $29(64.4)$ & $22(51.2)$ & 0.117 \\
\hline
\end{tabular}

Data are presented as number of patients (\%). The statistical significance was accepted with $\mathrm{P}$ values less than 0.05 for primary comparison among groups and 0.0083 for post-hoc multiple comparisons between pairwise groups (Bonferroni adjustment; 0.05/6). *P < 0.0083 compared to Group C.

Table 3. Severity of Sore Throat and Hoarseness during the First 24 Hours after Extubation

\begin{tabular}{|c|c|c|c|c|c|}
\hline & $\begin{array}{c}\text { Group C } \\
(\mathrm{n}=45)\end{array}$ & $\begin{array}{l}\text { Group Kpre } \\
(\mathrm{n}=47)\end{array}$ & $\begin{array}{l}\text { Group Kpost } \\
\quad(\mathrm{n}=45)\end{array}$ & $\begin{array}{c}\text { Group D } \\
(\mathrm{n}=43)\end{array}$ & $P$ value \\
\hline \multicolumn{6}{|c|}{ Sore throat $(0 / 1 / 2 / 3)$} \\
\hline \multicolumn{6}{|c|}{ Rest } \\
\hline $1 \mathrm{~h}$ & $2 / 11 / 13 / 19$ & $3 / 18 / 12 / 14$ & $3 / 11 / 10 / 21$ & $2 / 13 / 6 / 22$ & 0.563 \\
\hline $6 \mathrm{~h}$ & $13 / 17 / 5 / 10$ & $13 / 18 / 13 / 3$ & $12 / 17 / 12 / 4$ & $18 / 13 / 5 / 7$ & 0.130 \\
\hline $24 \mathrm{~h}$ & $25 / 11 / 5 / 4$ & $26 / 15 / 6 / 0$ & $20 / 16 / 6 / 3$ & $28 / 9 / 6 / 0$ & 0.277 \\
\hline \multicolumn{6}{|c|}{ Swallowing } \\
\hline $1 \mathrm{~h}$ & $1 / 5 / 13 / 26$ & $2 / 15 / 13 / 17$ & $1 / 8 / 14 / 22$ & $1 / 4 / 13 / 25$ & 0.215 \\
\hline $6 \mathrm{~h}$ & $1 / 16 / 15 / 13$ & $5 / 18 / 16 / 8$ & $5 / 13 / 16 / 11$ & $8 / 15 / 10 / 10$ & 0.406 \\
\hline $24 \mathrm{~h}$ & $3 / 30 / 7 / 5$ & $10 / 25 / 10 / 2$ & $8 / 17 / 17 / 3$ & $14 / 16 / 8 / 5^{*}$ & 0.013 \\
\hline \multicolumn{6}{|c|}{ Hoarseness $(0 / 1 / 2 / 3)$} \\
\hline $1 \mathrm{~h}$ & $3 / 12 / 23 / 7$ & $3 / 16 / 18 / 10$ & $5 / 12 / 18 / 10$ & $3 / 15 / 19 / 6$ & 0.920 \\
\hline $6 \mathrm{~h}$ & $8 / 22 / 12 / 3$ & $11 / 24 / 11 / 1$ & $6 / 23 / 15 / 1$ & $8 / 24 / 10 / 2$ & 0.910 \\
\hline $24 \mathrm{~h}$ & $11 / 28 / 6 / 0$ & $19 / 23 / 4 / 1$ & $16 / 22 / 7 / 0$ & $21 / 19 / 3 / 0$ & 0.312 \\
\hline
\end{tabular}

Data are presented as number of patients. Severity of sore throat was assessed using 4 graded scale: 0 , no sore throat; 1 , mild sore throat; 2 , moderate sore throat; 3 , sever sore throat. Severity of hoarseness was assessed using 4 graded scale: 0 , no hoarseness; 1 , mild hoarseness; 2 , moderate hoarseness; 3 , severe hoarseness. The statistical significance was accepted with $\mathrm{P}$ values less than 0.05 for primary comparison among groups and 0.0083 for posthoc multiple comparisons between pairwise groups (Bonferroni adjustment; 0.05/6). ${ }^{*} \mathrm{P}<0.0083$ compared to Group C.

Table 3. In the control group, the incidence of severe POST at rest and during swallowing was $42 \%$ and $57 \%$, respectively, at 1 hour but markedly reduced to $9 \%$ and $11 \%$, respectively, at 24 hours. At rest, POST severities were similar in the four groups at each time-point. During swallowing, POST severities were also similar at 1 hour $(P=0.215)$ and 6 hours $(P=0.406)$ but significantly different at 24 hours $(\mathrm{P}=0.013)$. Intergroup analysis revealed that the severity score of group $\mathrm{C}$ were different from that of group D $(\mathrm{P}=0.008)$ but similar to that of group Kpre or Kpost during swallowing at 24 hours after extubation. The incidences and severities of $\mathrm{PH}$ were comparable at all time-points (Tables 2 and 3).
In the PACU, the majority of patients in the four groups complained of pain in the operation site $(88.9 \%, 72.3 \%, 73.3 \%$ and $75.0 \%$ in group C, Kpre, Kpost and D, respectively, $\mathrm{P}=0.296$ ). Although NRS scores for pain in the four groups were comparable at all time-points after thyroidectomy, patients in group Kpre required significantly less analgesics than patients in group $\mathrm{C}$ at 1 hour after extubation (Table 4, P $=0.006$; Bonferroni-adjusted 95\% confidence interval of proportion differences; $0.07-0.38$ ). During 24 hours observation period, the incidences of nausea and vomiting were not different in the four groups (Table 4). No patient complained of gastritis, gastric bleeding, headache, renal dysfunction or hyperglycemia during postoperative 24 hours 
Table 4. Postoperative Outcome

\begin{tabular}{|c|c|c|c|c|c|}
\hline & $\begin{array}{l}\text { Group C } \\
(\mathrm{n}=45)\end{array}$ & $\begin{array}{l}\text { Group Kpre } \\
(\mathrm{n}=47)\end{array}$ & $\begin{array}{l}\text { Group Kpost } \\
\quad(\mathrm{n}=45)\end{array}$ & $\begin{array}{l}\text { Group D } \\
(\mathrm{n}=43)\end{array}$ & $\mathrm{P}$ value \\
\hline \multicolumn{6}{|c|}{ NRS of pain $(\mathrm{cm})$} \\
\hline $1 \mathrm{~h}$ & $5.0(3.0-6.0)$ & $4.0(2.0-5.0)$ & $4.0(3.0-5.0)$ & $4.0(3.0-5.0)$ & 0.083 \\
\hline $6 \mathrm{~h}$ & $2.0(1.0-4.0)$ & $2.0(1.0-4.0)$ & $2.0(1.0-3.5)$ & $1.0(1.0-2.0)$ & 0.323 \\
\hline $24 \mathrm{~h}$ & $1.0(0-3.0)$ & $1.0(0-2.0)$ & $1.0(0-2.0)$ & $1.0(0-2.0)$ & 0.688 \\
\hline \multicolumn{6}{|c|}{ Analgesic use } \\
\hline $1 \mathrm{~h}$ & $14(31.1)$ & $4(8.5)^{*}$ & $6(13.3)$ & $9(20.9)$ & 0.031 \\
\hline $6 \mathrm{~h}$ & $2(4.4)$ & 0 & 0 & 0 & 0.179 \\
\hline $24 \mathrm{~h}$ & $1(2.2)$ & 0 & 0 & 0 & 0.739 \\
\hline \multicolumn{6}{|l|}{ Nausea } \\
\hline $1 \mathrm{~h}$ & $10(22.2)$ & $11(23.4)$ & $13(28.9)$ & $15(34.9)$ & 0.522 \\
\hline $6 \mathrm{~h}$ & $2(4.4)$ & 7 (14.9) & $6(13.3)$ & $1(2.3)$ & 0.084 \\
\hline $24 \mathrm{~h}$ & 0 & $1(2.1)$ & $2(4.4)$ & 0 & 0.517 \\
\hline \multicolumn{6}{|c|}{ Vomiting } \\
\hline $1 \mathrm{~h}$ & 0 & $2(4.3)$ & $1(2.2)$ & $1(2.3)$ & 0.752 \\
\hline $6 \mathrm{~h}$ & 0 & $2(4.3)$ & $1(2.2)$ & 0 & 0.619 \\
\hline $24 \mathrm{~h}$ & 0 & 0 & 0 & 0 & \\
\hline
\end{tabular}

Data are presented as median with interquartile range or number of patients (\%). NRS: Numerical rating scale. The statistical significance was accepted with $\mathrm{P}$ values less than 0.05 for primary comparison among groups and 0.0083 for post-hoc multiple comparisons between pairwise groups (Bonferroni adjustment; $0.05 / 6) .{ }^{*} \mathrm{P}<0.0083$ compared to Group C.

observation period.

\section{Discussion}

In the present study, we evaluated the effects of two drugs with anti-inflammatory action on the incidence of POST in female thyroidectomy patients that had undergone general anesthesia with endotracheal intubation. Dexamethasone $10 \mathrm{mg}$ IV before induction significantly reduced the incidence and severity of sore throat during swallowing compared to placebo at 24 hours after tracheal extubation. On the other hand, IV ketorolac at a standard therapeutic dose $(30 \mathrm{mg})$ before induction or at the end of surgery failed to reduce the incidence and severity of POST during first 24 hours. Our finding shows that a single use of ketorolac is inadequate for the prevention of POST during first 24 hours after thyroidectomy when administered via the IV route, despite its potent anti-inflammatory efficacy.

Although multiple factors are considered to be responsible for the development of POST after endotracheal intubation, localized inflammatory response of airway mucosa in response to intubation process and presence of an ETT in the trachea plays a crucial role even after optimal short-term tracheal intubation [13]. In addition, ETT movement by neck hyperextension and surgical manipulation of the tissue adjacent airway during surgery may aggravate acute inflammatory responses, and consequently, leads to high incidence of POST in thyroidectomy patients. Therefore, the pharmacological mechanism of preventing POST is presumed to be based on anti-inflammatory activity of steroidal and non-steroidal medications.

Dexamethasone has been recommended to reduce inflammation-associated pain and edema in oral and dental surgeries because it is known to suppress the production of various inflammatory mediators by inhibiting phospholipase A2, which convert arachidonic acid to cyclooxygenase and lipoxygenase. The anti-inflammatory efficacy of IV dexamethasone in prevention of POST has been demonstrated after different types of surgery with endotracheal intubation [5,6]. Particularly in thyroidectomy patients, Wang et al. [14] reported that prophylaxis with dexamethasone $10 \mathrm{mg}$ IV reduced pain score than placebo at all times during first 24 hours postoperative period when a visual analog scale was used to assess POST intensity. However, the effect of dexamethasone on POST after endotracheal intubation in patients undergoing thyroidectomy was not clearly defined, because they did not assess the total incidence of POST or control the contributing factors such as ETT size, ETT cuff design and pressure, and airway management technique.

In the present study, the prophylactic efficacy of dexamethasone $10 \mathrm{mg}$ IV for reducing the incidence and severity of POST was revealed at 24 after extubation during swallowing, but not at rest. Our finding suggests that a single dose of systemic dexamethasone before induction of anesthesia significantly reduces POST in the late rather than early postoperative period in patients undergoing thyroidectomy. One reason for the lack of benefit from dexamethasone in early postoperative period has been low dosing in our patients. A dexamethasone dose of $10 \mathrm{mg}$, we chose in this study, has been demonstrated its 
POST-reducing efficacy in patients with minimal intensity of POST after diverse surgeries [5,6]. However, the dose-response relationship in specific procedure with high risk of POST has not been established. Previous studies showed less severity and lower incidence of POST in the late postoperative period (24-48 hours) than early postoperative period (1-6 hours) $[1,2,15]$. The action of dexamethasone begins at 1 hour and persists for 36-54 hours. The prolonged duration of action may be responsible for the clinical efficacy of dexamethasone in late postoperative period. However, greater dose of dexamethasone may be required for reducing POST in early postoperative period with higher incidence and greater severity of sore throat after thyroidectomy.

The anti-inflammatory efficacy of NSAID in prevention of POST has been demonstrated for topical application of a diclofenac patch, transdermal ketoprofen or gargling with benzydamine before induction of anesthesia [16-18]. In contrast, a single dose of IV diclofenac $75 \mathrm{mg}$ at induction of anesthesia failed to reduce the incidence or severity of sore throat during the first 18 hours after laparoscopic surgery [19]. The authors assumed that IV administration may result in a lower drug concentration than topical application, which lead to the lack of benefit from diclofenac in their study.

Because of its analgesic and anti-inflammatory efficacy by inhibiting prostaglandin biosynthesis, ketorolac has been considered as an alternative to glucocorticoid in the postoperative period after oral surgery $[9,20,21]$. The anti-inflammatory efficacy of ketorolac, despite being inferior to its analgesic activity, was found to be approximately twice as great as that of indomethacin and 3 times as great as that of naproxen in terms of suppressing edema in an animal model [22,23]. Acute inflammatory response to endotracheal intubation is supported by scientific evidence, which shows progressive increase in polymorphonuclear cells and cytokines in human trachea during intubation [24]. Incidence of POST may coincide with increased production of chemical mediators of inflammation at the surgical site. In thyroidectomy patients, POST occurs as early as at 1-2 hours and peaks at 6-20 hours and then subsides over 24-48 hours $[2,4,14]$, which supports our decision to assess POST over the first 24 hours. In this study, patients were received a single dose of ketorolac before induction of anesthesia or at the end of surgery and its clinical effects were expected in the early postoperative period because of relatively short onset (3-5 minutes) and intermediate half-life (5.5 hours) of IV ketorolac. However, regardless of timing of administration, no significant reduction of POST was found from a single dose of ketorolac $30 \mathrm{mg}$ IV during the first 24 hours compared to placebo. This lack of benefit from a single dose of ketorolac IV on POST reduction may be explained by suboptimal dose of ketorolac. A standard $30 \mathrm{mg}$ dose of IV ketorolac is known to significantly reduce pain and edema after oral surgery [20]. However, endotracheal intubation and surgical irritation in the present study may have generated a greater level of noxious stimulation over long period, and thus, led to more airway inflammation than oral surgery. In the present study, the preoperative administration of ketorolac was found to induce opioid sparing effect but not to reduce the incidence and severity of POST at 1 hour after extubation compared to placebo. These findings suggest that a different ketorolac dose regimen and timing of administration are necessary to prevent POST in intubated high risk patients.

The present study has some limitations. First, the dose of dexamethasone and ketorolac may not be equipotent in terms of anti-inflammatory efficacy. Dexamethasone $10 \mathrm{mg}$ IV has been shown to be effective for the reduction of POST after different types of surgery [5,6]. A single $30 \mathrm{mg}$ dose of ketorolac, which has been shown its ability to reduce inflammatory edema and pain after dental surgery [20,25], may be inadequate to provide anti-inflammatory efficacy sufficient to reduce POST in thyroidectomy patients. Accordingly, different inflammatory models may exhibit different anti-inflammatory dose-response relationship. Second, postoperative pain control might affect the incidence and severity of the POST. In this study, patients in the control group received more analgesics (fentanyl) compared with those in the other groups in the PACU, which may be one reason for the similar incidence and severity of POST, at least, between control and ketorolac groups.

In conclusion, the present study shows prophylactic dexamethasone $10 \mathrm{mg}$ IV significantly reduce the incidence and severity of postoperative sore throat at 24 hours after extubation as compared with placebo in thyroidectomy patients. A single dose of ketorolac $30 \mathrm{mg}$ IV administered preoperatively or intraoperatively failed to produce beneficial effect.

\section{ORCID}

Chunwoo Yang, http://orcid.org/0000-0002-9147-3879

Sung Mee Jung, http://orcid.org/0000-0001-5602-9011

Yu Kyung Bae, http://orcid.org/0000-0002-3396-3140

Sang-Jin Park, http://orcid.org/0000-0002-4838-2664

\section{References}

1. Ryu JH, Yom CK, Park DJ, Kim KH, Do SH, Yoo SH, et al. Prospective randomized controlled trial on the use of flexible reinforced laryngeal mask airway (LMA) during total thyroidectomy: effects on postoperative laryngopharyngeal symptoms. World J Surg 2014; 38 : 378-84. 
2. Jung TH, Rho JH, Hwang JH, Lee JH, Cha SC, Woo SC. The effect of the humidifier on sore throat and cough after thyroidectomy. Korean J Anesthesiol 2011; 61: 470-4.

3. Christensen AM, Willemoes-Larsen H, Lundby L, Jakobsen KB. Postoperative throat complaints after tracheal intubation. Br J Anaesth 1994; 73: 786-7.

4. Xu YJ, Wang SL, Ren Y, Zhu Y, Tan ZM. A smaller endotracheal tube combined with intravenous lidocaine decreases post-operative sore throat - a randomized controlled trial. Acta Anaesthesiol Scand 2012; 56: 1314-20.

5. Bagchi D, Mandal MC, Das S, Sahoo T, Basu SR, Sarkar S. Efficacy of intravenous dexamethasone to reduce incidence of postoperative sore throat: A prospective randomized controlled trial. J Anaesthesiol Clin Pharmacol 2012; 28: 477-80.

6. Thomas S, Beevi S. Dexamethasone reduces the severity of postoperative sore throat. Can J Anaesth 2007; 54: 897-901.

7. Jung H, Kim HJ. Dexamethasone contributes to the patient management after ambulatory laryngeal microsurgery by reducing sore throat. Eur Arch Otorhinolaryngol 2013; 270: 3115-9.

8. Ostrov CS, Sirkin SR, Deutsch WE, Masi RJ, Chandler JW, Lindquist TD. Ketorolac, prednisolone, and dexamethasone for postoperative inflammation. Clin Ther 1997; 19: 259-72.

9. Paiva-Oliveira JG, Bastos PR, Cury Pontes ER, da Silva JC, Delgado JA, Oshiro-Filho NT. Comparison of the anti-inflammatory effect of dexamethasone and ketorolac in the extractions of third molars. Oral Maxillofac Surg 2016; 20: 123-33.

10. Stout DM, Bishop MJ, Dwersteg JF, Cullen BF. Correlation of endotracheal tube size with sore throat and hoarseness following general anesthesia. Anesthesiology 1987; 67: 419-21.

11. Friedman PG, Rosenberg MK, Lebenbom-Mansour M. A comparison of light wand and suspension laryngoscopic intubation techniques in outpatients. Anesth Analg 1997; 85: 578-82.

12. Newcombe RG. Interval estimation for the difference between independent proportions: comparison of eleven methods. Stat Med 1998; 17: 873-90.

13. Puyo CA, Tricomi SM, Dahms TE. Early biochemical markers of inflammation in a swine model of endotracheal intubation. Anesthesiology 2008; 109: 88-94.

14. Wang JJ, Ho ST, Lee SC, Liu YC, Liu YH, Liao YC. The prophylactic effect of dexamethasone on postoperative nausea and vomiting in women undergoing thyroidectomy: a comparison of droperidol with saline. Anesth Analg 1999; 89: 200-3.

15. Ryu JH, Han SS, Do SH, Lee JM, Lee SC, Choi ES. Effect of adjusted cuff pressure of endotracheal tube during thyroidectomy on postoperative airway complications: prospective, randomized, and controlled trial. World J Surg 2013; 37: 786-91.

16. Rahimi M, Makarem J. Effects of diclofenac epolamine patch on postoperative sore throat in parturients after cesarean delivery under endotracheal general anesthesia. Acta Anaesthesiol Taiwan 2009; 47: 17-21.

17. Ozaki M, Minami K, Sata T, Shigematsu A. Transdermal ketoprofen mitigates the severity of postoperative sore throat : [Le kétoprofène transdermique réduit le mal de gorge postopératoire]. Can J Anaesth 2001; 48: 1080-3.

18. Agarwal A, Nath SS, Goswami D, Gupta D, Dhiraaj S, Singh PK. An evaluation of the efficacy of aspirin and benzydamine hydrochloride gargle for attenuating postoperative sore throat: a prospective, randomized, single-blind study. Anesth Analg 2006; 103: 1001-3.

19. Thang'a P, Kamya D, Mung'ayi V. Effects of intravenous diclofenac on postoperative sore throat in patients undergoing laparoscopic surgery at Aga Khan University Hospital, Nairobi: a prospective, randomized, double blind controlled trial. Afr Health Sci 2013; 13: 999-1006.

20. Pendeville PE, Van Boven MJ, Contreras V, Scholtes JL, Fosseur G, Lechien P, et al. Ketorolac tromethamine for postoperative analgesia in oral surgery. Acta Anaesthesiol Belg 1995; 46: 25-30.

21. Trindade PA, Giglio FP, Colombini-Ishikiriama BL, Calvo AM, Modena KC, Ribeiro DA, et al. Sublingual ketorolac and sublingual piroxicam are equally effective for postoperative pain, trismus, and swelling management in lower third molar removal. Oral Surg Oral Med Oral Pathol Oral Radiol 2012; 114: 27-34.

22. Rooks WH 2nd, Maloney PJ, Shott LD, Schuler ME, Sevelius H, Strosberg AM, et al. The analgesic and anti-inflammatory profile of ketorolac and its tromethamine salt. Drugs Exp Clin Res 1985; 11: 479-92.

23. Rooks WH 2nd, Tomolonis AJ, Maloney PJ, Wallach MB, Schuler ME. The analgesic and anti-inflammatory profile of (+/-)-5-benzoyl-1,2dihydro-3H-pyrrolo[1,2a]pyrrole-1-carboxylic acid (RS-37619). Agents Actions 1982; 12: 684-90.

24. Puyo CA, Dahms TE. Innate immunity mediating inflammation secondary to endotracheal intubation. Arch Otolaryngol Head Neck Surg 2012; 138: 854-8.

25. Ong KS, Tan JM. Preoperative intravenous tramadol versus ketorolac for preventing postoperative pain after third molar surgery. Int J Oral Maxillofac Surg 2004; 33: 274-8. 